\title{
Cross sectional survey to assess the self perception of oral health status reported by IGNOU students versus clinical diagnosis
}

\author{
Rutu C. Shah ${ }^{1}$, Harsh Shah ${ }^{2}$, Nisarg Chaudhary ${ }^{3}$, Ricky Pal Singh ${ }^{4, *}$, VasudhaSodani ${ }^{5}$, Amrita Pawar $^{6}$ \\ ${ }^{\mathbf{1}}$ Intern, ${ }^{\mathbf{2}}$ Reader \& HOD, ${ }^{\mathbf{3}}$ Reader, ${ }^{\mathbf{5}}$ Reader, Dept. of Pedodontics \& Preventive Dentistry, ${ }^{\mathbf{1 , 2 5}}$ ADC Dental College, Ahmedabad, \\ Gujarat, ${ }^{3}$ Siddhpur Dental College \& Hospital, Siddhpur, ${ }^{4}$ Senior Lecturer, Dept. of Public Health Dentistry, ${ }^{6}$ Senior Lecturer, \\ Dept. of Prosthodontics, I. T. S. Centre for Dental Studies \& Research, Muradnagar, Ghaziabad, India
}

*Corresponding Author:

Email: rickypalsingh@its.edu.in

\begin{abstract}
Introduction: Oral health is considered as a gateway /reflection to general health and thus it is of pivotal importance for everyone. With the advent of the $21^{\text {st }}$ century, oral health awareness and prevention of oral diseases has become the agenda nationally and internationally. Despite, various awareness campaigns via mode of audio aids, audio-visual aids, and street play etc. oral health diseases are on a constant increase.

Materials and Method: Descriptive cross sectional survey was carried out on 259 IGNOU students to assess:

1. Self-perceived dental \& periodontal status versus clinically diagnosed dental and periodontal health.

2. Assessment of questionnaire using large value population survey.

3. Establish a relationship between dental health status and understanding the public perception of oral health.

Results: Total 259 patients 16 males and 4 females) 136 males and 123 females with the mean age of $19 \pm 2.3$ years participated in the survey. The overall consensus of the patients were that $52 \%$ (134) of the participants perceived that they have a bad dental health status compared to $50.5 \%$ (131) who were clinically found to have bad dental health status, (p < 0.000001, McNemar test). Conclusion: Self-assessment questionnaires were of moderate value in evaluating oral health status each within the individual and public levels, although perception levels of health were beyond that of disease and illness. Literature also reflects that occasional level of awareness of the general public will influence care-seeking behaviour and will signify the importance of oral health promotion and is also crucial for public health actions.
\end{abstract}

Keywords: Self- assessment, Oral health, Clinical diagnosis.

\section{Introduction}

Oral health is considered as a gateway to general health and thus it is of pivotal importance for everyone. With the advent of the $21^{\text {st }}$ century, oral health awareness and prevention of oral diseases has become the agenda nationally and internationally. Despite, various awareness campaigns via mode of audio aids, audio-visual aids, and street play etc. oral health diseases are on a constant increase. Caries \& periodontal diseases are the foremost dental pathologies which are prevalent around the globe and some measures need to be taken to prevent these diseases. ${ }^{1}$ The key to the future lies among the youth of today, thus it is the need of the hour to make them aware of oral diseases and modes of prevention for the same. It is recommended to visit your dentist twice a year, but most of the population does not follow it up leading to several dental problems. In India, the perception for the oral health varies among the communities, and it is heavily relied on the self-perception of the individual. ${ }^{2}$

Comparison of self-reported oral health and normative oral health could demonstrate the efficacy of oral health status of the individual. Literature reflects the various studies to validate the sensitivity and specificity of self-reported and clinically examined oral conditions. Clinical examination of these diseases are expensive and utilization of dental services are expensive, nationwide survey's prove to be effective way of reducing the burden of diseases and diagnosis of any lesion. Many researches have been done in the past regarding the oral health status depending upon the DMFT and Oral hygiene index. Thus, to reduce the global burden of oral health and create awareness among the youth regarding the oral habits and prevention of oral diseases, a questionnaire was designed to assess the oral health knowledge and habits among the students of Indra Gandhi National Open University (IGNOU). Hence, present survey aimed to focus the self-perception of participants using a selfreported questionnaire. ${ }^{3,4}$

\section{Aim}

To assess the self-perceived Oral-health status of IGNOU students using self-administered questionnaire as compared to clinically diagnosed dental and periodontal health status.

\section{Objectives}

4. To assess self-perceived dental \& periodontal status versus clinically diagnosed dental and periodontal health.

5. Assessment of questionnaire using large value population survey.

6. Establish a relationship between dental health status and understanding the public perception of oral health. 


\section{Materials and Methods \\ Methodology}

Descriptive cross sectional survey was carried out among the students of Indra Gandhi National Open University (IGNOU). All the students participated in the study, and Institutional ethical clearance wasobtained from the Ahmedabad Dental College \& Hospital, Ahmedabad.

\section{Sampling technique}

The total students 259 studying at IGNOU were selected and included in the study after obtaining the informed consent and were applied to the selfadministered questionnaire with 11 items following clinical diagnosis.

\section{Clinical examination}

Dental status (DMFT) \& periodontal status (CPI): Each participant was taken to the dental examination room. During the study period oral examinations were performed in accordance with the WHO standardized methodology and were conducted by five examiners and then the results were supervised and calibrated by the principal investigator. No dental radiographs were taken. Dental caries, missing and filled tooth were examined using DMFT index and periodontal status was examined using Community periodontal index using WHO-calibrated probe. ${ }^{5}$

\section{Questionnaire}

The questionnaire was provided to the subject prior to the dental examination, so as to avoid any potential effect or bias of the dentist's examination and diagnosis on the subject's self-perception. Every participant was given a self-administered questionnaire. There were total 11 questions, 9 questions were close ended and 2 open ended.

Following were two open ended questions:

1. "What is your opinion regarding the health status of your teeth?"

2. "What is your opinion regarding the health status of your gums?"

Possible answers were categorized to "excellent", "good", "not so good", and "bad". For research and analysis the answers were categorised in 2 classes. The first being Good self-perceived assessment which included the answers "Excellent" and "Good" and the second being Bad self-perceived assessment which included the answers "Not so good" and "Bad". 6

The clinical examinations which are considered as gold standard and the self-perceived assessment questionnaire were compared for: ${ }^{7}$

1. Sensitivity: Total number of individuals who perceive having the disease compared to those who are diagnosed clinically as having the disease.

2. Specificity: The proportion of individuals who perceive not having the disease compared to those who are diagnosed clinically as not having the disease.

3. Positive predictive value (PPV): The proportion of individuals who have the disease (according to the clinical examination) from the total group that perceive having the disease.

4. Negative predictive value (NPV): The proportion of individuals who do not have the disease (according to the clinical examination) from the total group that perceive not having the disease.

5. Overall proportions: The proportions of clinically diagnosed disease among the total population and self-perceived disease among the total population.

Sensitivity and specificity rates are presented with their appropriate 95\% CI (Confidence Intervals). The Data collected was subjected to statistical analysis using SPSS version 21. Qualitative variables were elaborated by frequencies, and percentages. Quantitative variables were summarized by means and standard deviations. Test of association was done using McNemar test as appropriate, p-value for statistical significance set at $5 \%$.

\section{Results}

Out of the 259 participants, 136 were males and 123 were females with the mean age of $19 \pm 2.3$ years (Fig.1). Table $1 \&$ Table 2 represent the sensitivity and specificity of DMFT index with prediction of dental caries (normative and assessed) and Table 3 represent the CPI index predictor for periodontal health.

Table 1: Sensitivity and Specificity for perceived dental status according to different cut-off points

\begin{tabular}{|l|c|c|}
\hline Cut-off point & $\begin{array}{c}\text { Sensitivity } \\
(\mathbf{\%})\end{array}$ & $\begin{array}{c}\text { Specificity } \\
(\mathbf{\%})\end{array}$ \\
\hline DMFT $=8$ & $64 \%$ & $61 \%$ \\
\hline DMFT $=1$ & $52 \%$ & $80 \%$ \\
\hline D $=1$ & $43 \%$ & $86 \%$ \\
\hline
\end{tabular}

Table 2: Perceived and normative assessment of dental health

\begin{tabular}{|l|c|c|c|}
\hline $\begin{array}{c}\text { Normative } \\
\text { Perceived }\end{array}$ & $\begin{array}{c}\text { DMFT } \\
>9\end{array}$ & $\begin{array}{c}\text { DMFT } \\
\mathbf{0 - 9}\end{array}$ & Total \\
\hline Bad & TP 84 & FP 50 & 134 \\
\hline Good & FN 47 & TN 78 & 125 \\
\hline Total & 131 & 128 & 259 \\
\hline
\end{tabular}

$\mathrm{TP}=$ True Positive $\cdot \mathrm{FP}=$ False Positive $\cdot \mathrm{FN}=$ False Negative $\cdot \mathrm{TN}=$ True Negative $\cdot$ Sensitivity $(\mathrm{TP} /(\mathrm{TP}+\mathrm{FN}))=0.64(95 \% \mathrm{CI} 0.62-0.66) \cdot$ Specificity $(\mathrm{TN} /(\mathrm{TN}+\mathrm{FP}))=0.61(95 \%$ CI $0.59-0.63) . \cdot$ Positive Predictive Value $(\mathrm{TP} /(\mathrm{TP}+\mathrm{FP}))=0.63 \cdot$ Negative Predictive Value $(\mathrm{TN} /(\mathrm{TN}+\mathrm{FN}))=0.62 \cdot$ Overall Proportions $=134$ participants $(52 \%)$ reported having bad dental health status compared to 131 (50.5\%) clinically caries diagnosed subjects (McNemar test, $\mathrm{p}=$ $<0.000001)$. 
Table 3: Perceived and normative assessment of periodontal health

\begin{tabular}{|l|c|c|c|}
\hline $\begin{array}{l}\text { Normative } \\
\text { Perceived }\end{array}$ & $\begin{array}{c}\text { CPITN } \\
\mathbf{3 - 4}\end{array}$ & $\begin{array}{c}\text { CPITN } \\
\mathbf{0 - 2}\end{array}$ & Total \\
\hline Bad & TP 21 & FP 80 & 101 \\
\hline Good & FN 13 & TN 145 & 158 \\
\hline Total & 34 & 225 & 259 \\
\hline
\end{tabular}

$\mathrm{TP}=$ True Positive $\cdot \mathrm{FP}=$ False Positive $\cdot \mathrm{FN}=$ False Negative $\cdot \mathrm{TN}=$ True Negative $\cdot$ Sensitivity $(\mathrm{TP} /(\mathrm{TP}+\mathrm{FN}))=0.62(95 \% \mathrm{CI} 0.61-0.64)$. Specificity $(\mathrm{TN} /(\mathrm{TN}+\mathrm{FP}))=0.64(95 \%$ CI $0.061-0.66) . \cdot$ Positive Predictive Value $(\mathrm{TP} /(\mathrm{TP}+\mathrm{FP}))=0.21 \cdot$ Negative Predictive Value $(\mathrm{TN} /(\mathrm{TN}+\mathrm{FN}))=0.92 \cdot$ Overall Proportions $=101$ participants $(39 \%)$ reported having bad periodontal health status compared to $34(31.2 \%)$ clinically periodontal disease diagnosed subjects (McNemar test, $\mathrm{p}=<0.000001$ ).

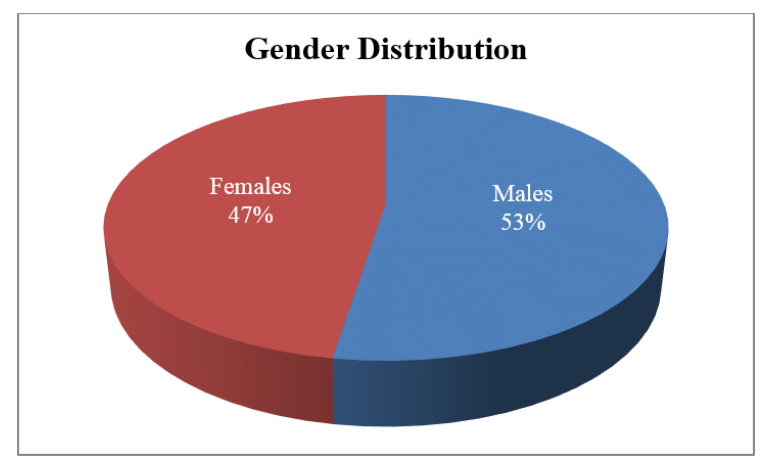

Fig. 1: Gender wise distribution

\section{Dental Status}

3 cut-off points were selected for operational definitions:

1. DMFT $=9$ (in accordance with mean DMFT of $9.22 \pm 3.85$ of present study participants): DMFT scores $0-9=$ "Good" dental-status and DMFT $>9$ $=$ "Bad" dental-status,

2. DMFT $=1$ : DMFT score $0=$ "Good" dental-status and DMFT $\geq 1=$ "Bad" dental-status.

3. $\mathrm{D}$ (component of DMFT) $=1$ : D score $0=$ "Good" dental-status and $\mathrm{D} \geq 1=$ "Bad" dental-status.

According to the clinical examination, 131 (50.5\%) participants were found to have DMFTmore than 9 and $128(49.4 \%)$ participants were found to have DMFT of 8 or less. ${ }^{8-10}$

According to the questionnaire, 134 (52\%) participants reported to have bad dental health status and $125(48.2 \%)$ participants reported to have good dental health status.

The sensitivity for perceived dental status was found to be 0.64 (95\% CI 0.62-0.66), while the specificity was found to be 0.61 (95\% CI $0.59-0.63)$.

The PPV for perceived dental status was found to be 0.63 , whereas the negative predictive value was found to be 0.62 .
Regarding the overall proportions, 52\% (134) of the participants perceived that they have a bad dental health status compared to $50.5 \%$ (131) who were clinically found to have bad dental health status $(\mathrm{p}<0.000001, \mathrm{McNemar}$ test $)$.

\section{Periodontal Health}

Periodontal health was assessed using CPI index and was defined as follows:

CPI scores $0-2$ (healthy, bleeding or calculus as the worst score) were considered in"Good" periodontal status. $^{8}$

CPI scores $3-4$ (shallow and deep periodontal pockets, respectively) were considered in "Bad" periodontal status.

According to the clinical examination of all the participants, 34 (13.12\%) participants were found to have CPI scores of 3 or 4 and $225(86.87 \%)$ participants were found to have CPITN of 0 to 2 .

According to the questionnaire filled by 259 participants 101 (38.99\%) participants reported to have bad periodontal health status and 158 (61\%) participants reported to have good periodontal health status.

The sensitivity for periodontal status was found to be $0.62(95 \%$ CI $0.61-0.64)$, while the specificity was found to be 0.64 (95\% CI 0.061-0.66).

The PPV for periodontal status was found to be 0.21 , whereas the NPV was found to be 0.92 .

Regarding the overall proportions, 39\% (101) of the participants perceived having bad periodontal health status compared with $31.2 \%$ (34) who were clinically diagnosed as having bad periodontal health status ( $\mathrm{p}<$ 0.000001, McNemar test).

\section{Discussion and Conclusion}

In the current study, DMFT and CPI indices were used for the assessment of dental caries status and periodontal diseases status which are considered as gold standard for examination and validation. The examinations were carried out by team of 5 dentists and all were calibrated before the commencement of the survey $(\mathrm{K}=0.81)$.

The chair side clinical examination and selfperceived assessment questionnaires were compared for sensitivity, specificity, PPV, NPV and overall proportions. It has been recommended that sensitivity and specificity should be collaborated and the values of both should be combined and termed as adequate validity. Predictive values of positive and negative tests are influenced by the prevalence of the disease in the population, in which the test is performed, so that the lower the prevalence, the lower will be the predictive value.

Perceived oral health status in the current study was found to be moderate specificity $0.61 \& 0.64$ for dental-caries and periodontal-disease with moderate sensitivity as well. Positive predictive value for 
periodontal disease was on lower side for periodontal disease 0.21 and moderate for dental caries 0.63 respectively.

Self-reporting of gingival and periodontal health status as well as self-assessment of the presence of cavity are found to be neither helpful nor undefeated. Gilbert et al contradicted and stated that four out of eighteen predictors were frail and can be modified..$^{2-4}$

Robinson et al recommended that self-reported interview knowledge is not helpful for assessing the presence of dental decay. In their study, twenty six out of forty five participants had decay or additional decayed teeth, nineteen out of sixty five participants were found to possess decay by clinical examination. ${ }^{2}$ Research has also indicated that individuals knowledge and assessment is dependent on clinical signs like blackish discoloration, fractured tooth in determining dental caries. Joshipura et al. instructed that valid selfreported measures may offer a time-and-costefficient different for giant epidemiologic studies. ${ }^{8}$

Thus it can be concluded that, self-assessment questionnaires were of moderate value in evaluating oral health status each within the individual and public levels, although perception levels of health were beyond that of disease and illness. Literature also reflects that occasional level of awareness of the general public will influence care-seeking behaviour and will signify the importance of oral health promotion and is also crucial for public health actions.

\section{References}

1. Barmes DE. A global view of oral diseases: today and tomorrow. Community Dent Oral Epidemiol 1999;27:2-7.

2. Robinson PG, Nadanovsky P, Sheiham A. Can questionnaires replace clinical surveys to assess dental treatment needs of adults? J Public Health Dent 1998;58:250-3.

3. Gilbert AD, Nuttall N. Self - reporting of periodontal health status. Brit Dent J 1999;186:241-4.

4. Helöe LA. Comparison of dental health data obtained from questionnaires, interviews and clinical examination. Scand J Dent Res. 1972;80:495-9.

5. Kononen M, Lipasti J, Murtomaa H. Comparison of dental information obtained from self - examination and clinical examination. Community Dent Oral Epidemiol 1986;14:258-60.

6. Palmqvist S, Söderfeldt B, Arnbjerg D. Self - assessment of dental conditions: validity of a questionnaires. Community Dent Oral Epidemiol 1991;19:249-51.

7. Vered Y, Sgan-Cohen HD. Self - perceived and clinically diagnosed dental and periodontal health status among young adults and their implications for epidemiological surveys. BMC Oral Health 2003;13;3(1):3.

8. Joshipura KJ, Pitiphat W, Douglass CW. Validation of self-reported periodontal measures among health professionals. J Public Health Dent 2002;62:115-121.

9. Singh R, Ajith Krishnan CG, Kalantharakath, T. (2014). Recent Advances in Caries Diagnosis. Saarbrucken: LAP LAMBERT Academic Publishing.

10. Bafna H, Ajith Krishnan CG, Kalantharkath T, Kalyan P, Singh R. An In-vitro evaluation of the effect of anticandidal herb (olive) on streptococcus mutans. IJOHR 2015;1(1):20. 